\title{
Faculty experience of flipping the classroom: Lessons learned
}

Melinda Hermanns, Jerri L. Post, Belinda Deal

School of Nursing, The University of Texas at Tyler, Tyler, Texas, United States

Received: May 17, 2015

Accepted: July 5, 2015

Online Published: July 27, 2015

DOI: $10.5430 /$ jnep.v5n10p79

URL: http://dx.doi.org/10.5430/jnep.v5n10p79

\begin{abstract}
"Flipping the classroom" is gaining in popularity. The flipped classroom permits active learning and student engagement whereby the traditional class time is transformed into an active learning experience in which students can apply knowledge and interact with their peers and perform "hands-on" activities. This descriptive phenomenological study focused on the lived experiences of nursing faculty implementing a flipped classroom into the medical/surgical curriculum. The faculty's experience with implementing and adapting to non-traditional teaching learning methods of the "flipped" classroom in their medical/surgical classes is shared. The themes expressed by faculty are presented in the two overall categories of: Faculty concerns and Faculty benefits. Lastly, lessons learned and recommendations are also presented.
\end{abstract}

Key Words: Phenomenological, Flipped classroom, Faculty experience

\section{INTRODUCTION}

Faculty can choose from a variety of novel methods to deliver course instruction. One concept that has gained much attention among the faculty community is the pedagogical model of a flipped classroom. In a flipped classroom, the conventional lecture methods and the assignment of outside activities is reversed; students review the learning material outside of the classroom and class time is used for the assimilation and application of class content. Using a flipped classroom, students listen and watch lecture videos outside the classroom (on their own time) and the in-class time is utilized to engage students using a variety of classroom activities. This methodology allows students the opportunity to take more of an active role in their learning. Evidence supports a move from teacher-centered classrooms to student-centered classrooms. ${ }^{[1]}$ While the flipped classroom may help to promote active learning, it also helps to personalize and individualize the learning activities. While this approach may be different from what faculty members are accustomed to, a change may be warranted. The "sacred cow", "we have always done it this way" is no longer justification to barricade change. Using a traditional didactic approach, the majority of the faculty's time is spent disseminating information through lectures. In a flipped classroom, the students are at the center of learning, rather than the faculty. Additionally, this approach increases the faculty-student interaction as well as student-to-student interaction, and, the faculty becomes the facilitator of active student learning. Weimer calls for this change. "Hopefully the next 15 years will see a continued transformation that ends with students as active and involved as their teachers" (para 5).

Faculty members at a southern university embraced the idea of a flipped classroom and were eager to pilot this innovative

\footnotetext{
*Correspondence: Melinda Hermanns; Email: mhermanns@uttyler.edu; Address: School of Nursing, The University of Texas at Tyler, Tyler, Texas, United States.
} 
learning to the undergraduate medical-surgical curriculum. The faculty's experience in implementing a flipped classroom and lessons learned throughout the process will be discussed. The purpose of the pilot study was to explore the lived experience of faculty regarding the process of adapting to non-traditional innovative methods of teaching/learning through a descriptive phenomenology study. The research question that guided this study was: What is the experience of students and faculty during adaptation to non-traditional teaching learning methods in adult health nursing courses? The students' experience is reported a previous manuscript. ${ }^{[2]}$

The teaching/learning strategy of flipping the classroom was piloted in both Medical-Surgical I and Medical-Surgical II. Hutchings and Quinney ${ }^{[3]}$ defined a "flipped classroom" as, "providing course materials, frequently in the form of video lectures, for students to engage with outside the classroom, enabling in-class time to be repurposed for student-centered collaborative learning activities" (p. 106). Traditional lectures were recorded for students to access and review remotely online. The goal was to take the Medical-Surgical (Med/Surg) curriculum to new levels of learning through recorded lectures and simulated critical thinking hands on activities (i.e., role play, games, and case studies) by flipping the classroom. Class time consisted of face-to-face simulated activities that were used as a learning tool to make the medical-surgical content more engaging and meaningful.

\section{Literature review}

The flipped classroom is a term commonly used to describe a teaching method centered on student lecture in the form of videos and other resources like websites and podcasts in the home environment, while classroom time is focused on interactive learning activities to promote collaborative problem solving facilitated by teachers. ${ }^{[4]}$ The Flipped Learning Network $^{[5]}$ defines flipped learning as,

"Flipped learning is a pedagogical approach in which direct instruction moves from the group learning space to the individual learning space, and the resulting group space is transformed into a dynamic, interactive learning environment where the educator guides students as they apply concepts and engage creatively in the subject manner". ${ }^{[5]}$

Originally implemented in 2008 by two high school chemistry teachers, Bergmann and Sams, in the state of Colorado, ${ }^{[4]}$ the flipped learning pedagogy is currently being utilized in learning environments on an international and interdisciplinary basis. A review of the literature demonstrates the flipped learning method being incorporated into the learning environment in Australia, ${ }^{[6]}$ Asia, ${ }^{[7]}$ and Canada. ${ }^{[8]}$ Different academic disciplines utilizing the flipped learning pedagogy include business, ${ }^{[4]}$ law schools, ${ }^{[8]}$ pharmacy schools ${ }^{[9]}$ nursing schools, ${ }^{[10]}$ and medical schools. ${ }^{[11]}$ While many of the studies found the flipped learning pedagogy to be primarily positive experiences, such as increased student engagement and collaboration; ${ }^{[4-11]}$ there were also negative outcomes, such as lack of student understanding, an increased time commitment related to pre-class preparation, and time needed to train the instructors on the new pedagogy. ${ }^{[4,6,8,9]}$

One method of evaluating the flipped classroom that has received little attention is the faculty's perspective of implementing the flipped learning pedagogy into the curriculum. No studies were located that specifically focused on the faculty's perspectives of a flipped classroom. However, there were a number of studies that included faculty issues such as mindset, time commitments, training, etc. along with the student issues. While it is important to understand how students respond to the implementation of a new learning pedagogy, it is equally important to understand the benefits and barriers as experienced by the faculty who prepare and teach in the flipped classroom.

\section{METHOD}

\subsection{Design}

A descriptive phenomenological research study was conducted over concurrent fall and spring semesters. The setting was a public university in the southern United States containing a primary campus and two satellite campuses. Participants included faculty members teaching in a bachelor of science in nursing (BSN) program from the main campus and the two satellite campuses, who were recruited via email to participate in the study.

\subsection{Ethical considerations}

Institutional Review Board (IRB) approval was obtained through the university and informed consent was signed by all participants. Interviews were conducted in a private location and were recorded. The participants' personal information was kept confidential and research data was protected in a locked, password protected computer that only the researchers had access to.

\subsection{Data collection}

Following Benner, Sutphe, Leonard and Day's ${ }^{[12]}$ recommendation, qualitative data were collected through focus group interviews. Focus groups are an appropriate method for conduction of phenomenological research. ${ }^{[13]}$ A total of six faculty members participated in one focus group. The ages ranged from 50 to 61 years, with a mean age 55 years. 
All of the participants identified themselves as Caucasian females. Faculty participating in this study had an average of 10 years of teaching experience, but no previous experi- ence in implementing a flipped classroom. The focus group interview was digitally recorded and lasted approximately 45 minutes. The interview questions are provided in Table 1.

Table 1. Example faculty interview questions

- What was the biggest challenge from your (faculty) perspective for implementing this new method of teaching (and include
- $\quad$ What campus)?
- Were you apprehensive about teaching this new method? How so?
- What kind of support did you need to adapt to this new type of teaching?
- $\quad$ Dow did the new methods force students to become more self-directed learners?
Within the different types of alternative learning (simulation, case study, etc.), which one did you think was the best learning
experience for the students?
Of all the things identified this afternoon, what are the most important things we, as researchers, need to know about these
non-traditional teaching methods?

\subsection{Data analysis}

The researchers transcribed the recorded focused interviews verbatim. Prior to ending the focus group, the researcher summarized the responses and asked for clarification of meanings from the participants. Data were analyzed using Giorgi' ${ }^{[14]}$ phenomenological analytic method. Giorgi's method involves searching data for common themes that describe the meaning of an experience through the viewpoint of the participants. The following steps were taken:

(1) "The researcher first reads the whole description in order to get a sense of the whole"[14] (p. 5). Two researchers read each transcript in its entirety.

(2) "The researcher then goes back to the beginning of the description and begins to reread it" ${ }^{\text {"[14] }}$ (p. 5). Two experienced qualitative researchers read and re-read each transcript, using line by line analysis to extract meanings of the faculty participants' experience.

(3) "The researcher transforms the data, still basically in the words of the subject, into expressions that are more directly revelatory of the psychological import of what the subject said" ${ }^{[14]}$ (p. 5). Meanings were explored and separated into categories and themes.

(4) "The direct and psychologically more sensitive expressions are then reviewed and with the help of free imaginative variation an essential structure of the experience is written" ${ }^{[14]}$ (p. 6). Data were coded manually and over a $90 \%$ consistency of intercoder reliability was obtained.

(5) "The essential structure is then used to help clarify and interpret the raw data of the research" ${ }^{[14]}$ (p. 6). As meanings, categories, and themes developed, the lived experience of faculty participating in this innovative teaching strategy known as "flipping the classroom" became clearer and repetitive themes emerged.

\section{FINDINGS}

The challenges experienced by faculty in adopting a flipped classroom were addressed in a descriptive phenomenology study of faculty teaching in an undergraduate Medical/Surgical course who utilized a flipped classroom approach for the delivery of the Medical/Surgical classroom content. The faculty involved in the pilot study revealed a number of challenges in implementing the "flipped classroom". The themes expressed by faculty are presented in the two overall categories of: Faculty concerns and Faculty benefits.

\subsection{Faculty concerns}

\subsubsection{Students}

Initially, faculty concerns were many. First and foremost, faculty members were concerned about the students. In the beginning, students had a number of questions as the students were accustomed to having immediate feedback via a question/answer format in the traditional classroom. "My concern is that students are concerned. They want immediate feedback. If they have a question, they want it immediately. They can do a lot of things, but that's not the same as being in a classroom and holding up your hand." To address this concern, faculty created discussion boards so students could post their questions and concerns. However,

"We have found in Med/Surg, when we use the discussion board, not all students are using it. Only about a fourth of the students are even getting on and using it. But there are a lot of comparables, I mean, students are fairly comfortable 
getting on there and posting different questions and then us coming back and answering them. And they've got really good questions, too. It's not just about the course, it's about content."

“The way I put it, you know, "If you've got a question, everyone else does too, please post your question here."

Faculty also talked about the students' perception of time, and the student data supported this as well.

"That was our perception of a lot of our students, too, because except for exam day and then a couple of three Tuesday mornings, we are expecting them to be here, because it was clinical time, and so they perceived it as double time and it really wasn't. But it was their perception, because they still had to be there every Tuesday morning."

Unanimously, faculty stated,

"Well, our ultimate goal was that we would include student outcomes in terms of critical thinking and application... This is our first semester and we learned a lot. We've already been meeting and talking about what we did well and what we definitely need to improve on and what needs to go out the window."

\subsubsection{Apprehension}

As a faculty team dedicated to delivering quality instruction and excellence in teaching, faculty shared that they had feelings of apprehension from their inexperience in using video lectures and voiced concerns of, "is it on, is it off, did I have problems, did I forget to turn it off when I answered a question? Nervousness." One faculty stated, “... I recall I turned it on and off inappropriately because we missed a couple of slides. I was kind of nervous..." Some stated that their "biggest issue is our Southern accent, our down-home talk sometimes and just to be more cognizant of how you sound and where you're placing, or starting and stopping the recordings..." Others expressed apprehension regarding the format change.

"In the back of my mind, I'm trying to figure out how I'm going to re-do my lectures over the summer for our new text book because I enjoy lecturing in front of a group of people and if I'm not lecturing to a group of people, I'm afraid I'm just going to be very monotone and this is this and da, da, and not have that lively examples, or... So I'm really hesitant about trying to move to this new lecture because I'm going to miss lecturing in front of folks."

Again striving for excellence, an ongoing concern was the delivery and quality of the video recordings.

"That's a big difference to us. I have, a couple of videos I re-recorded you know, in the office, because of some glitch in the system and it's not the same. You look out there in the audience and when you see all these blank looks staring back at you, you know that they didn't get it and you've got to go back and do something more for them. And when you are just there in front of the computer screen you don't get that feedback. Managing video recordings also required new skills to be sure the recording was turned on and turned off in the right locations."

\subsubsection{Logistics}

Logistics such as rooms/space was a big challenge; for the alternative learning sessions, there was no room available and the students would go outside on the "grass". "When we had such large numbers, we really didn't have enough space; we had really logistics concerns." Other challenges included scheduling of space for each clinical group to meet because lab space is shared with other courses and availability varied by campus and day of the week.

Anytime there is a new methodology that is being introduced or there is a change of any type there is some apprehension related to that. Sometimes faculty may seem like they do not feel in control because of technological mishaps. For example, the lecture capture program required new skills related to recording from a desk top computer as well as trouble shooting any unforeseen events like lack of hard drive storage space to complete the recording. Faculty needed to develop new interactive activities for the semester, which meant recording a new lecture and a new clinical activity, which equated to an increased in their workload. To adapt to this new type of teaching, support in terms of available space and room and time was needed-in addition to supplies and technological support.

Other concerns were that students would put course material on the internet, thus violating copyright, privacy and Health Insurance Portability and Accountability Act (HIPPA) regulations. Faculty were challenged partly because of the additional time needed to develop multiple simulation exercises. A policy was instituted and students signed a form stating that they would not post and/or violate any copyright issues. 


\subsubsection{Time}

Faculty voiced concerns regarding the amount of time it required for students to review the content and were unsure of whether this improved the students' confidence and ability to understand and apply the content. Managing recordings also required technology adeptness to properly capture relevant content. The additions of small interactive group sessions were used to reinforce the online lectures and enhance critical thinking to make the content more engaging and meaningful. However, this small group activity took more preparation time for the new active learning experiences and presented the problem of finding space and time to conduct multiple small group sessions.

\subsubsection{Change}

Faculty expressed concern with "the change": the change from the traditional delivery of instruction to the flipped classroom. "Switching to more interactive activities required more instructor involvement with students on each of the campuses; whereas before, we did team teaching and only one instructor was responsible for that material... now all of us had to be responsible for all of it all the time. That was a big change." Preparation for the new method included a semester of planning on a course by course basis. In hindsight, more preparation spread out over two semesters, a smaller pilot study with one course to start with, the ability of faculty to opt out or voice concerns, and looking at the effects related to the whole nursing program would have been helpful.

Changes can be physically and emotionally draining for the faculty in part because of student expectations, but also the increase in faculty's expectations and workload. This new method increased faculty's workload. Faculty stated, "We are trying to allow preparation time for the learning activities and the interactive learning activities."

\subsubsection{Frustration}

Another concern shared by faculty was frustration.

“They (students) didn't watch the videos and they didn't do the readings for the learning activities. The learning activities were designed to supplement and strengthen the material so that there would be a better understanding, but (the students) still needed to have some knowledge about the information that was being presented. You know, it wasn't interactive; it included student participation. They couldn't come in unprepared. Yet many of them came unprepared so they weren't able to interact as well."

\subsection{Faculty benefits}

\subsubsection{Effective learning}

The benefits shared by the faculty were: learning in small groups was effective as well as the hands-on simulation was beneficial to the students' learning. "The best part of the experience was... the fact that they can only talk about the particular learning activity they were responsible for but it was felt that simulation was good, case study and gaming, but thought that breaking off into small groups was a positive thing. And Med/Surg felt like anything with hands on was a total benefit." Another benefit was the opportunity to expand their learning opportunities, as evidenced by "... the issue was that they (students) didn't see it in the clinical setting; that it was this format gave them an opportunity to be able to at least have some exposure whereas there's none in the traditional classroom." In this format, "every student is getting similar information, whereas in their different clinical experiences, they are getting different settings. Or they may not get it at all." Overall, the flipped model allowed the faculty to be creative in their teaching.

A huge benefit was that learning occurred, and, the students felt confident in their learning.

"So, having the labs where they do actually get hands-on experience and actually see things for the first time and really realize what their responsibilities are. I think that gives them a chance to learn in a different way, because I've had students who asked that we do the simulations. They feel so much more confident and they feel so much more prepared when they actually see a code in the hospital setting. They say, "It's just like what y'all taught us." They felt much more secure about... oh, they're going to go get the crash cart, what they're doing, they knew the steps involved. So it helps them to be more prepared for clinicals and they go in with a little bit more confidence than they would if they had nothing prior to that experience.

"They (the students) feel better prepared and they are more confident, I think, than they would be. I know that when we have them come in and do simulations sometimes, they're scared. But after working with them and spending some time with them, I think their confidence stays up. As (Name) said, they are social learners and they feed off each other and they do very well."

"I think the only other thing we talked about was the confidence level of learning in a pretty safe environment and then actually going out there. 
Doing it in lab and actually putting your hands on it within a safe area for them; it increases their confidence when they do go in ICU. They feel better prepared and they are more confident than they would be. I know that when we have them come in and do simulations, sometimes they're scared. But after working with them and spending some time with them, their confidence stays up."

\subsubsection{Remediation}

An additional benefit was the opportunity to remediate, when needed. "I felt, and we discussed it as a group too, that we were able to do remediation even if the students chose to not prepare for that particular one, like the respiratory one. We set up simulations that really honed in on respiratory to make sure that they understood the material; because sometimes we might find that a student in clinical shifts didn't take care of someone on a ventilator, whereas, we were able to have that material available in the simulation lab. So even if they didn't prepare in advance, I still felt that they, even if they only got a little piece out of it, like understood better how a ventilator works or about the trachs or something. I think pretty much every student came away with a lot of new information and some with maybe just a little piece. But I felt like it was worth our time and preparation whereas we won't have to do as much time and preparation every single semester at the same campus." Faculty also expressed that this methodology was a benefit as it addressed the various learning needs of the students.

"Since we have learners that learn at different ways and for some people it's great and for others it could not be so great; but the more different kinds of variations in activities you can have, the more you are going to hit all of them so that everybody is learning. When I talk with students, a lot of them said, 'You know, it's nice to have both the lecture and the (videos).' So if they want to come to class and they are confused about something in particular, then they can come and talk to the instructor. But then, again, they can go back home and review it. And for those students who really like to do well on the exams, they really liked having the videos because they could go back and make sure that they knew everything about that material. It just really depends on the student. I think an ideal balance would be to have maybe a combination."

"As a supplement, I think Tegrity is a great idea."
In summary, this flipped approach allowed the students to become more self-directed learners. Even though faculty expressed that they thought the students were self-directed learners, this teaching method offered the students the opportunity to apply what they were learning, as opposed to just listening to a lecture. The small group, "hands-on" simulations permitted social learning. It afforded them the opportunity to learn together, and, learning in a supportive and safe environment with experience faculty serving as their facilitators.

\section{Discussion}

The flipped classroom constitutes a paradigm shift for the faculty; moving away from the traditional means of being in the front of the room and lecturing to creating a collaborative learning environment that supports cooperative contribution from faculty and students, recognizing that there will be a concomitant change in the role of students as well. Students may be more accustomed to being more of a passive participant in their learning journey and have expectations of a traditional lecture. However, the "flipped" classroom shifts more of the responsibility for learning on the students. Learning activities become more dynamic; you witness increased communication as well as confidence in learning as evidenced by the hands-on experience. The faculty's role becomes more of a facilitator. The facilitator role allows faculty the opportunity to devote more time to individual students.

\section{Lessons learned and recommendations}

Flipping the classroom can be an effective teaching modality that can result in an improved student learning environment; however, faculty must first be prepared to change from a traditional lecture format where the student is primarily passive to a teaching/learning format that puts an emphasis on student engagement through active learning techniques. We learned that change takes time, change is hard, and there will be obstacles. These obstacles may include apprehension, both from the faculty as well as the students. "There was a lot of apprehension because any time you change you may be comfortable in your old way of doing things and you've done it before, you know how it works and with anything new, you don't know how it's going to work. I like to feel in control. As instructors, we know what we're doing, and I felt concerned because this is a brand new thing."

As one of the faculty shared, "One of the most important aspects that researchers needed to know about these nontraditional teaching methods were the importance of considering the following: room space, time, flexibility, and student/faculty ratio." Additionally, "the most important things 
that we as researchers need to know is: supply, space, time, money, flexibility, more hands on and that they, um, in working with these students in this simulated learning, or doing learning activities, rather, that it gives the faculty the opportunity to recognize what the student really doesn't know." As a result of faculty experiences implementing this new teaching strategy, the following recommendations are suggested:

- Plan ahead and allow ample time for reflection and development.

- Increase faculty engagement in innovation.

- Embrace change and don't be afraid to try innovative teaching strategies.

- Keep the focus on the students - evaluate and reevaluate.

- Share with the students how the innovation benefits their education efforts.

- Provide faculty adequate administrative support for new technology innovations.

Moving forward, adopting new and innovative teaching/learning methods, such as "flipping the classroom" is one way of ensuring a place for nursing education in the digital future.

\section{SUMMARY}

This study focused on the lived experiences of nursing faculty implementing a flipped classroom into their med/surgical curriculum. The flipped classroom permits active learning and student engagement. The traditional class time is transformed into an active learning experience in which students can apply knowledge and interact with their peers and perform "hands-on" activities. It is anticipated that a new method of teaching (active learning including simulations in small groups and recorded lectures instead of face-to-face lecture) will be a positive learning experience for students and faculty. This descriptive phenomenological study was designed to explore the means by faculty to adapt to this change in teaching and learning, and identify motivators and obstacles to the new approaches as viewed by students and faculty.

In conclusion, if you are considering "flipping" your classroom, be prepared to devote adequate time to prepare so you can successfully implement. This may require a significant number of hours, so be fully committed. Realize that you may encounter unexpected obstacles along the way, but your efforts will be rewarded when you see that your students are engaged and enjoying learning!

\section{CONFlicts OF InTEREST Disclosure}

The authors declare that there is no conflict of interest.

\section{REFERENCES}

[1] Weimer M. What we have and haven't learned. 2015. Available from: http://www.facultyfocus.com/articles/teaching -professor-blog/what-we-have-and-havent-learned/

[2] Post JL, Deal B, Hermanns M. Implementation of a flipped classroom: Nursing students' perspectives. J Nurs Educ and Prac. 2015; 5(6). http://dx.doi.org/10.5430/jnep.v5n6p25

[3] Hutchings M, Quinney A. The flipped classroom, disruptive pedagogies, enabling technology and wicked problems: Responding to 'the bomb in the basement'. The Elec J e-Learning. 2015; 13(2): 105-118.

[4] Findlay-Thompson Mombourquette P. Evaluation of a flipped classroom in an undergraduate business course. Bu Educ \& Accred. 2014; 6(1): $63-70$

[5] Flipped Learning Network. Definition of flipped learning. 2014.

[6] Butt A. Student views on the use of a flipped classroom approach: Evidence from Australia. Business Education \& Accreditation. 2014; 6(1): 33-43.

[7] Joanne CSM, Lateel F. The flipped classroom: Viewpoints in Asian Universities. Educ in Med J. 2014; 6(4): 20-26.
[8] Sankoff P. Taking the instruction of law outside the lecture hall: How the flipped classroom can make learning more productive and enjoyable (for professors and students). Alberta Law Review. 2014; 51(4): 891-906.

[9] Wong TH, Ip EJ, Lopes I, et al. Pharmacy Students' performance and perceptions in a flipped teaching pilot on cardiac arrhythmias. Am Jof Pharma Educ. 2014; 78(10): 1-6. PMid:25657372 http://dx.doi.org/10.5688/ajpe7810185

[10] Ratta CBD. Flipping the classroom with team-based learning in undergraduate nursing education. Nurs Educ. 2014; 40(2): 71 74. PMid:25402712 http://dx.doi.org/10.1097/NNE.00000 00000000112

[11] Morgan H, Mclean K, Chapman C, et al. The flipped classroom for medical students. The Clinical Teacher. 2015; 12: 155-160. PMid:26009948 http://dx.doi.org/10.1111/tct.12328

[12] Benner P, Sutphe M, Leonard V, et al. Educating nurses: A call for radical transformation. San Francisco: Jossey-Bass; 2010.

[13] Krueger RA, Casey MA. Focus groups: A practical guide for applied research. 4th Edition. Thousand Oaks: Sage Productions; 2009.

[14] Giorgi A. The descriptive phenomenological psychological method. J Phen Psych. 2014; 43: 3-12. 